\title{
Contribution of Substance Use in Acute Injuries With Regards to the Intent, Nature and Context of Injury: A CHIRPP Database Study
}

Catherine Michaud-Germain ${ }^{1}$, Pier-Alexandre Tardif ${ }^{2}$, Alexandra Nadeau ${ }^{2}$, Ann-Pier Gagnon ${ }^{2}$, Éric Mercier $^{3}$

1. Family and Emergency Medicine, Laval University, Quebec, CAN 2. Axe Santé Des Populations Et Pratiques Optimales En Santé, Centre De Recherche Du Chu De Québec - Université Laval, Quebec, CAN 3. Emergency Department, CHU De Québec - Université Laval, Quebec, CAN

Corresponding author: Éric Mercier, eric.mercier@fmed.ulaval.ca

\section{Abstract \\ Introduction}

Using the Canadian Hospitals Injury Reporting and Prevention Program (CHIRPP) sentinel surveillance system, the objective of this study was to compare intent, circumstances, injury type and patient demographics in patients who used a substance prior to the injury versus those who did not use any substances.

\section{Methods}

Data were retrospectively collected from November $1^{\text {st }} 2016$ to October $31^{\text {st }} 2017$. All patients presenting to the Hôpital de l'Enfant-Jésus ED following trauma were included, aside from those who left without seeing a physician or had no physical injury (e.g., overdose without any trauma was excluded). Patients voluntarily completed a standardised form or agreed to be contacted later. Medical charts of all attendances were reviewed by the CHIRPP's program coordinator. Substance use included illicit drugs, medications for recreational purposes, alcohol or other used either by the patient or another person involved.

\section{Results}

A total of 12,857 patients were included. Substance use was involved in 701 (5.5\%) cases and was associated with injuries sustained by males $(\mathrm{p}<.001)$. The mean age of patients injured while using substances was 42.8 years, compared to 45.5 years in those who did not use substances $(\mathrm{p}<.001)$. Substance use was involved in $3.6 \%$ of unintentional injuries, compared to $26.2 \%$ of injuries intentionally inflicted by other and $38.9 \%$ for self-inflicted injuries $(p<0.0001)$. When substances were used, the odds of intentional injuries were 7.5 times greater compared to non-intentional injuries (95\% CI 6.7, 8.5). Burns, head injuries and polytraumas were more prevalent when drugs or alcohol were involved.

Received 04/09/2020

Review began 04/16/2020 Review ended 09/02/2020 Published 09/06/2020

๑) Copyright 2020

Michaud-Germain et al. This is an open access article distributed under the terms of the Creative Commons Attribution License CC-BY 4.0., which permits unrestricted use, distribution, and reproduction in any medium, provided the original author and source are credited.

\section{Conclusion}

This study outlines the significant contribution of substance use in intentional injuries, suggesting that it could potentially be beneficial to specifically target patients who present with deliberate physical injuries in preventive and therapeutic interventions offered in the ED.

Categories: Emergency Medicine, Other, Trauma

Keywords: trauma, intentional injury, intoxication, self-harm, emergency medicine

\section{Introduction}

Alcohol and drug use was found to be associated with traumatic injuries [1]. It was estimated that substance use disorder has caused 318,000 deaths globally in 2016 [2]. It has been shown that the odds of injury for those individuals consuming specifically alcohol were 5.0 times greater compared to non-exposure individuals in general population. Among drivers, those odds of injury were almost of 15 times greater [3]. Concerning illicit drugs, it has been shown that traumatic patients who screened positive were more likely to develop infectious complications [4]. Among teenagers, one study has shown that alcohol, marijuana and pain reliever use disorders are significantly associated with self and other-directed violence [5]. Another study has raised a red flag concerning a high rate of children (13 to 19 years) positive for alcohol or drugs following a trauma-related injury, especially among those with intentional mechanism of injury [6]. However, substance use and trauma is difficult to associate together as a wide array of terms is used to define a substance use and patterns of trauma [7]. Nevertheless, vigilance should be called for when facing a patient with a trauma-related injury to adequately treat or refer him. The best way to improve the quality of care of people who have been potentially injured under the influence of substances is to increase awareness 
While most studies that have explored the link between substance use and injuries in the emergency department (ED) among adults focused on the substances' nature [8-10], data relative to the patients' and injuries' characteristics associated with a general substance use are lacking. To our knowledge, only one other study has examined simultaneously the characteristics of injuries caused during substance use and intent status of the injury in a socioeconomic country similar to Canada [11]. However, it also focused on substances' nature.

Our objective was to compare intent, circumstances, injury type and patient demographics in patients who used a substance prior to the injury versus those who did not use any substances.

\section{Materials And Methods}

\section{Data source}

The Canadian Hospitals Injury Reporting and Prevention Program (CHIRPP) is a sentinel surveillance system conducted under the supervision of the Public Health Agency of Canada and designed to analyze events' circumstances and identify risk factors that prevention strategies could target [12]. In this context, each injured patient presenting to a Canadian ED in which the CHIRPP program is implemented was asked to voluntarily complete a standardised form or to be contacted at a future date regarding this injury. More specifically, questions pertaining to understand how the injury occurred and what was the patient doing, the etiology of the injury, the factors contributing to the injury, the moment and the emplacement where the injury occurred, and finally the age and sex of the patient. In the case of intoxicated patients, invitation to fill the form was done only before discharge, when patients were sober again. All attendances were later reviewed by the CHIRPP's program coordinator, who completed the unfilled or incomplete forms based on medical charts (including the nature of the injury, injured body part and treatment received).

\section{Population and variables}

This is a retrospective study in which data collection was undertaken at the Hôpital de l'Enfant-Jésus, a University affiliated hospital which is one of the three trauma centres in the Province of Quebec and a participating hospital into the CHIRPP program. All patients presenting to the Hôpital de l'Enfant-Jésus ED between November 1st 2016 and October 31st 2017 and seeking medical care for a traumatic injury or intoxication were included. Considering the focus on acute injuries, patients without any physical injury were thereafter excluded, along with those who left before seeing a physician since their information was unavailable. Moreover, because of potentially missing data, out-of-province/country patients were also excluded. Substance use was a categorical variable that indicated if illicit drugs, medications for recreational purposes, alcohol or other were used either by the patient or another person involved. It was considered as a factor in the injury event occurrence for values 'yes' and 'suspected'. The intent of injury is dichotomized into the database between unintentional and intentional, the latest including self-harm, assaults and maltreatment. The injuries were categorized according to context, nature, body parts and intent as per the CHIRPP's classification. The contexts of injury were grouped into eight different categories (see Appendix for details concerning items into each category).

\section{Data analysis}

Continuous and categorical variables were described using means (standard deviation) and proportions, respectively. The association between intoxication and categorical or continuous variables was evaluated using two-tailed Fisher's exact test or Student's t-test with Satterthwaite correction for unequal variances. The association between intoxication status and intent of injury was assessed using relative risks (RR) and 95\% confidence intervals (CI) obtained with a modified Poisson regression model adjusted for age and sex [13]. Analyses were performed using Statistical Analysis System 9.4 (SAS Institute Inc., Cary, NC, USA). The level of statistical significance for all tests was set at $\mathrm{p}<0.05$.

\section{Results}

During the study period, 16,275 patients visited the Hôpital de l'Enfant-Jésus ED following a trauma. Following the exclusion of patients out-of-province/country, those who left before seeing a physician and those without any physical injury, 12,857 patients were included. Of these, $56.8 \%(n=7,302)$ were male and a great majority $(\mathrm{n}=10,973,85.3 \%)$ lived in urban areas.

\section{Association with substance use}

Substance use was involved in 701 (5.5\%) cases and was associated with injuries sustained by males $(\mathrm{p}<$ .0001) (Table 1). The mean age of patients injured while using substances was 42.8 years, compared to 45.5 years in those who did not use substances $(\mathrm{p}<.001)$. Compared to patients with unintentional injuries, those reporting intentional injuries were significantly more likely to report substance use (39.4\% vs $5.1 \%$, p < 0.0001). The most favourable context for injuries in people who have used substance was during motor vehicle accident (11.7\%), followed by low-risk activities (5.4\%), while sports (17.5\%) and work (15.7\%) were 


\section{Cureus}

the two most predominant contexts of injuries for those with no substance involved. Wound, head injuries and traumatic brain injury (TBI), and musculoskeletal injuries were the three most observed mechanisms in both groups. Proportions of burns, wounds, head injuries and TBI, and polytraumas were however significantly higher when substances were used $(\mathrm{p}<0.02)$. Injuries primarily affected the head and neck when a substance was involved, while the spine and extremities were most implicated when no substance was involved. Supplemental material presents the patient characteristics stratified by intoxication status, but also classified by age categories.

\begin{tabular}{|c|c|c|c|}
\hline & Substance used $(n=701)$ & Substance unused $(n=12,156)$ & P-value \\
\hline \multicolumn{4}{|l|}{ Sociodemographic } \\
\hline Age, mean (SD) & $42.8(18.0)$ & $45.5(24.1)$ & $<0.0001^{*}$ \\
\hline Sex & - & - & $<0.0001^{\star}$ \\
\hline Female, n (\%) & 206 (29.4) & $5,349(44.0)$ & - \\
\hline Male, n (\%) & $495(70.6)$ & 6,606 (56.0) & - \\
\hline Geographic status & - & - & 0.60 \\
\hline Urban, n (\%) & $603(86.0)$ & $10,370(85.3)$ & \\
\hline \multicolumn{4}{|l|}{ Intent of injury } \\
\hline Unintentional, n & $425(60.6)$ & $11,530(94.9)$ & \multirow{2}{*}{$<0.0001^{\star}$} \\
\hline Intentional, $\mathrm{n}$ & 276 (39.4) & $626(5.1)$ & \\
\hline Inflicted by others & 127 & 358 & - \\
\hline Self-inflicted & 79 & 125 & - \\
\hline Other or unknown & 70 & 143 & - \\
\hline \multicolumn{4}{|l|}{ Injury } \\
\hline \multicolumn{4}{|l|}{ Context, n (\%) } \\
\hline Work & $3(0.4)$ & $1905(15.7)$ & $<0.0001^{*}$ \\
\hline Motor vehicle collision & $82(11.7)$ & $1243(10.2)$ & 0.21 \\
\hline Other types of transport & $18(2.6)$ & $390(3.2)$ & 0.35 \\
\hline Low-risk activities & $38(5.4)$ & $916(7.5)$ & $0.04^{\star}$ \\
\hline High-risk activities & 0 & $134(1.1)$ & $0.01^{*}$ \\
\hline Sports & $34(4.9)$ & 2132 (17.5) & $<0.0001^{\star}$ \\
\hline Aggressive attitude & $29(4.1)$ & $68(0.6)$ & $<0.0001^{*}$ \\
\hline Information missing & 0 & $60(0.5)$ & 0.06 \\
\hline \multicolumn{4}{|l|}{ Nature, n (\%) } \\
\hline Burn & $22(3.1)$ & $229(1.9)$ & $0.02^{\star}$ \\
\hline Electrocution & 0 & $35(0.3)$ & 0.26 \\
\hline Foreign body & $10(1.4)$ & 347 (2.8) & $0.02^{\star}$ \\
\hline Bite & $6(0.9)$ & $133(1.1)$ & 0.71 \\
\hline Asphyxia & $2(0.3)$ & $10(0.1)$ & 0.14 \\
\hline Wound & $375(53.5)$ & $5125(42.2)$ & $<0.0001^{*}$ \\
\hline Traumatic amputation & $1(0.1)$ & $64(0.5)$ & 0.27 \\
\hline Musculoskeletal & $295(42.1)$ & 6139 (50.5) & $<0.0001^{\star}$ \\
\hline Head injuries and TBI & $211(30.1)$ & 1408 (11.6) & $<0.0001^{\star}$ \\
\hline
\end{tabular}




\section{Cureus}

Polytrauma $^{\dagger}$

52 (7.4)

276 (2.3)

$<0.0001^{\star}$

Body part implicated, $\mathrm{n}(\%)$

Head \& neck

408 (58.2)

3477 (28.6)

$<0.0001^{*}$

Spine

$56(8.0)$

Trunk

$82(11.7)$

1277 (10.5)

$0.03^{*}$

$1252(10.3)$

0.24

Extremities

$241(34.4)$
$<0.0001^{*}$

TABLE 1: Characteristics of physically injured patients seen by an emergency physician stratified by intoxication status

†More than three injuries; TBI: traumatic brain injury; ${ }^{*}<0.05$

\section{Association with intend}

Intentional injuries occurred in 902 (7.0\%) cases, and were also associated with a lower average age (p < $.0001)$ and male sex $(\mathrm{p}<.0001)$ (Table 2). A higher ratio of patients who were victims of assault lived in urban areas $(\mathrm{p}=0.03)$. When substances were used, the odds of intentional injuries were 7.5 times greater compared to non-intentional injuries (95\% CI 6.7, 8.5). 


\section{Cureus}

\begin{tabular}{|c|c|c|c|}
\hline & Intentional ( $\mathrm{n}=902$ ) & Unintentional $(n=11,955)$ & P-value \\
\hline \multicolumn{4}{|l|}{ Sociodemographic } \\
\hline Age, mean (SD) & 33.6 (15.4) & $46.2(24.1)$ & $<0.0001^{*}$ \\
\hline Sex & - & - & $<0.0001^{*}$ \\
\hline Female, n (\%) & $298(33.0)$ & $5,257(44.0)$ & - \\
\hline Male, n (\%) & $604(67.0)$ & 6,698 (56.0) & - \\
\hline Geographic status & - & - & $0.003^{\star}$ \\
\hline Urban, n (\%) & $800(88.7)$ & $10,173(85.1)$ & - \\
\hline \multicolumn{4}{|l|}{ Injury } \\
\hline \multicolumn{4}{|l|}{ Context, n (\%) } \\
\hline Work & $83(9.2)$ & 1825 (15.3) & $<0.0001^{\star}$ \\
\hline Motor vehicle collision & $19(0.2)$ & $1306(10.9)$ & $<0.0001^{\star}$ \\
\hline Other types of transport & $1(0.1)$ & 407 (3.4) & $<0.0001^{\star}$ \\
\hline Low-risk activities & $31(3.4)$ & $923(7.7)$ & $<0.0001^{*}$ \\
\hline High-risk activities & 0 & 134 (1.1) & $0.001^{*}$ \\
\hline Sports & $34(3.8)$ & 2132 (17.8) & $<0.0001^{*}$ \\
\hline Aggressive attitude & $89(9.9)$ & $8(0.07)$ & $<0.0001^{*}$ \\
\hline Information missing & 0 & $60(0.5)$ & $0.03^{*}$ \\
\hline \multicolumn{4}{|l|}{ Nature, n (\%) } \\
\hline Burn & $17(1.9)$ & $234(2.0)$ & 0.88 \\
\hline Electrocution & 0 & $35(0.3)$ & 0.17 \\
\hline Foreign body & $35(3.9)$ & 322 (2.7) & $0.04^{*}$ \\
\hline Bite & $74(8.2)$ & $65(0.5)$ & $<0.0001^{*}$ \\
\hline Asphyxia & $9(1.0)$ & $3(0.03)$ & $<0.0001^{*}$ \\
\hline Wound & 537 (59.3) & 4963 (41.5) & $<0.0001^{*}$ \\
\hline Traumatic amputation & 0 & $65(0.5)$ & $0.03^{*}$ \\
\hline Musculoskeletal & 297 (32.9) & 6137 (51.3) & $<0.0001^{*}$ \\
\hline Head injuries and TBI & 125 (13.9) & 1494 (12.5) & 0.23 \\
\hline Polytrauma $^{\dagger}$ & $36(4.0)$ & $292(2.4)$ & $0.004^{\star}$ \\
\hline \multicolumn{4}{|l|}{ Body part implicated, n (\%) } \\
\hline Head \& neck & 402 (44.6) & $3483(29.1)$ & $<0.0001^{*}$ \\
\hline Spine & $33(3.7)$ & 1300 (10.9) & $<0.0001^{*}$ \\
\hline Trunk & $112(12.4)$ & 1222 (10.2) & $0.04^{*}$ \\
\hline Extremities & $400(44.4)$ & 7009 (58.6) & $<0.0001^{*}$ \\
\hline
\end{tabular}

TABLE 2: Characteristics of physically injured patients seen by an emergency physician stratified by intent status

†More than three injuries; TBI: traumatic brain injury; * $<0.05$ 
Compared to patients with unintentional injuries, those reporting intentional injuries were significantly more likely to sustain their injuries via aggressive attitude $(9.9 \%$ vs $0.07 \%, p<0.0001)$ toward themselves or resulting from a fight with a third party. The second context in frequency among intentional injuries is during work. Proportions of foreign body injuries, bite, asphyxia, wounds and polytraumas were significantly more frequently sustained intentionally $(\mathrm{p}<0.04)$.

\section{Discussion}

This is the first study using the CHIRPP database that portrays the contribution of substance use, regardless of the substance's nature, and the intend surrounding the acute injuries.

Key findings of this study highlight the substantial contribution of substance use to intentional injuries seen in the ED (39.4\% vs 5.1\%, p < 0.0001). This concurs with a random sample of ED patients in Vancouver (British Columbia, Canada) in which alcohol and recreational drug use, alone or in combination, were both strongly associated with intentional injuries [11]. As opposed to other studies relying on patients' urine or blood analysis, this study allowed for these bilateral associations to be brought into light by considering that substance use was also a contributing factor when someone other than the patient was intoxicated and involved in the injury. Another interesting discovery is that people who harm themselves will do so in a fit of anger, almost as much as when they are working.

The ED provides a unique opportunity for screening and early intervention for behaviours such as alcohol and substance use [10]. It is often the interface between the traditional health care system and vulnerable populations such as homeless persons [14], domestic violence victims [15] and older adults who are known to be at risk of violence-related events and substance abuse [16]. Various studies support the implementation of substance use screening tools for trauma patients in the ED $[1,10]$ and our results suggest that patients with deliberate physical injuries could potentially deserve greater screening.

The results also stress the importance of making intervention procedures available for the intentionally injured population. Unfortunately, some physicians still perceive brief interventions for substance use as ineffective despite how they were shown to decrease consumption, arrests, recidivism and injuries [1]. For instance, ED-initiated interventions to reduce subsequent suicidal behavior in high-risk patients [17] as well as ED-based programs aiming to reduce alcohol-related violence have been successfully implemented [18]. Alcohol intoxication has been linked to trauma recurrence [19]. Furthermore, patients with self-harm injuries are at known high risk of recidivism [20,21]. In that context, individualized interventions would be beneficial, but those types of ED-based interventions are infrequently available.

\section{Limitations}

Using patients from the CHIRPP program allowed a larger sample size. However, the conclusions reached should be cautiously generalized since the sample was not population-based and some subgroups might be underrepresented due to the hospital's status and location. In addition, the associations found cannot be interpreted in terms of causation, notably due to study design being retrospective and modelling (possible residual confounding). Nevertheless, systematic and standardized data collection allowed to representatively picture consultations for acute injuries in the ED of a tertiary trauma centre in Quebec, Canada. Considering intentional injuries, we do not have the information as to whether it was the victim, the assailant, or even both individuals who were intoxicated. In addition, the few cases of assaults or selfharm did not permit to create two distinct groups for comparison regarding the intent. Details on injuries and poisoning circumstances were not specifically studied, for which the use of verbatim would have added other limitations. With that said, this is of minor importance considering the aim of the study was not to describe the mechanism of injuries but rather to determine the types of injuries in which substance use played a significant role. Moreover, a misclassification bias is probable since solely CHIRPP variables were used. However, this bias is likely negligible since a recent report suggests CHIRPP variables have very high sensitivity; data mining with narrative codes would not have improved the classification's accuracy [22]. Finally, as data were self-reported or extracted from the medical record, an underestimation relative to the contribution of substance use is possible. Further details regarding the psychological [23] and homelessness [24] history of patients, as well as their financial status [25], would have potentially allowed additional conclusions regarding substance use and intend in acute injury.

\section{Conclusions}

This study, using the CHIRPP sentinel surveillance system, outlines the fact that a significant proportion of the population were injured because they were using substances, especially those whose injuries were intentional or the results of aggression. It could potentially be beneficial to target patients with deliberate physical injuries in preventive and therapeutic interventions offered in the ED. It stands to reason that encouraging the use of screening tools, biopsychosocial assessment (including evaluation of substance use) and brief interventions in this population, as well as ensuring adequate training of ED staff for this purpose, should also be considered as strategies to limit the considerable impact of substance use on intentional injuries. 


\section{Cureus}

\section{Appendices}

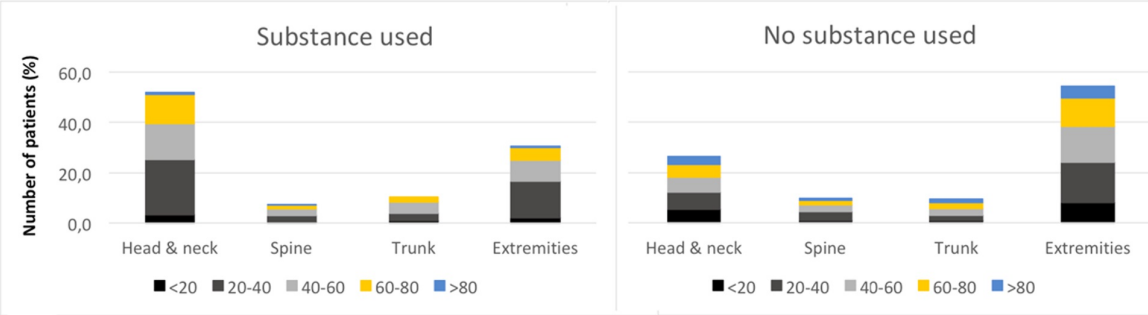

\begin{tabular}{|l|l|l|l|l|l|l|} 
Comparisons between substance used and substance unused (p value) \\
\hline Head \& neck & $<20$ & $20-40$ & $40-60$ & $60-80$ & $>80$ \\
\hline Spine & $0.006^{*}$ & $<0.001^{*}$ & $<0.001^{*}$ & $<0.001^{*}$ & 0.6 \\
\hline Trunk & 0.29 & $0.005^{*}$ & 0.40 & 0.80 & 0.85 \\
\hline Extremities & $0.04^{*}$ & 0.83 & $0.04^{*}$ & 0.86 & 0.13 \\
\hline & $0.01^{*}$ & $<0.001^{*}$ & $<0.001^{*}$ & $<0.001^{*}$ & 0.89 \\
\hline
\end{tabular}

FIGURE 1: Body parts injured by intoxication status and by age category

${ }^{*} p<0.05$

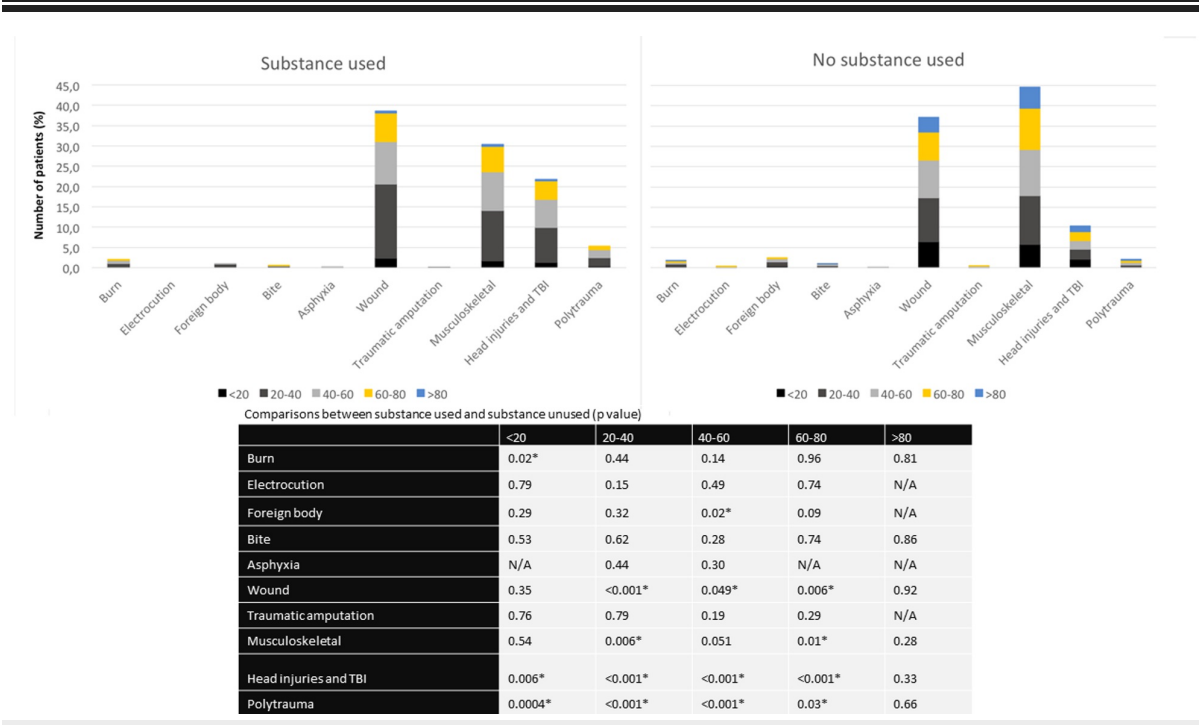

FIGURE 2: Nature of injury by intoxication status and by age category

TBI: Traumatic brain injury; ${ }^{*} \mathrm{p}<0.05$ 


\section{Cureus}

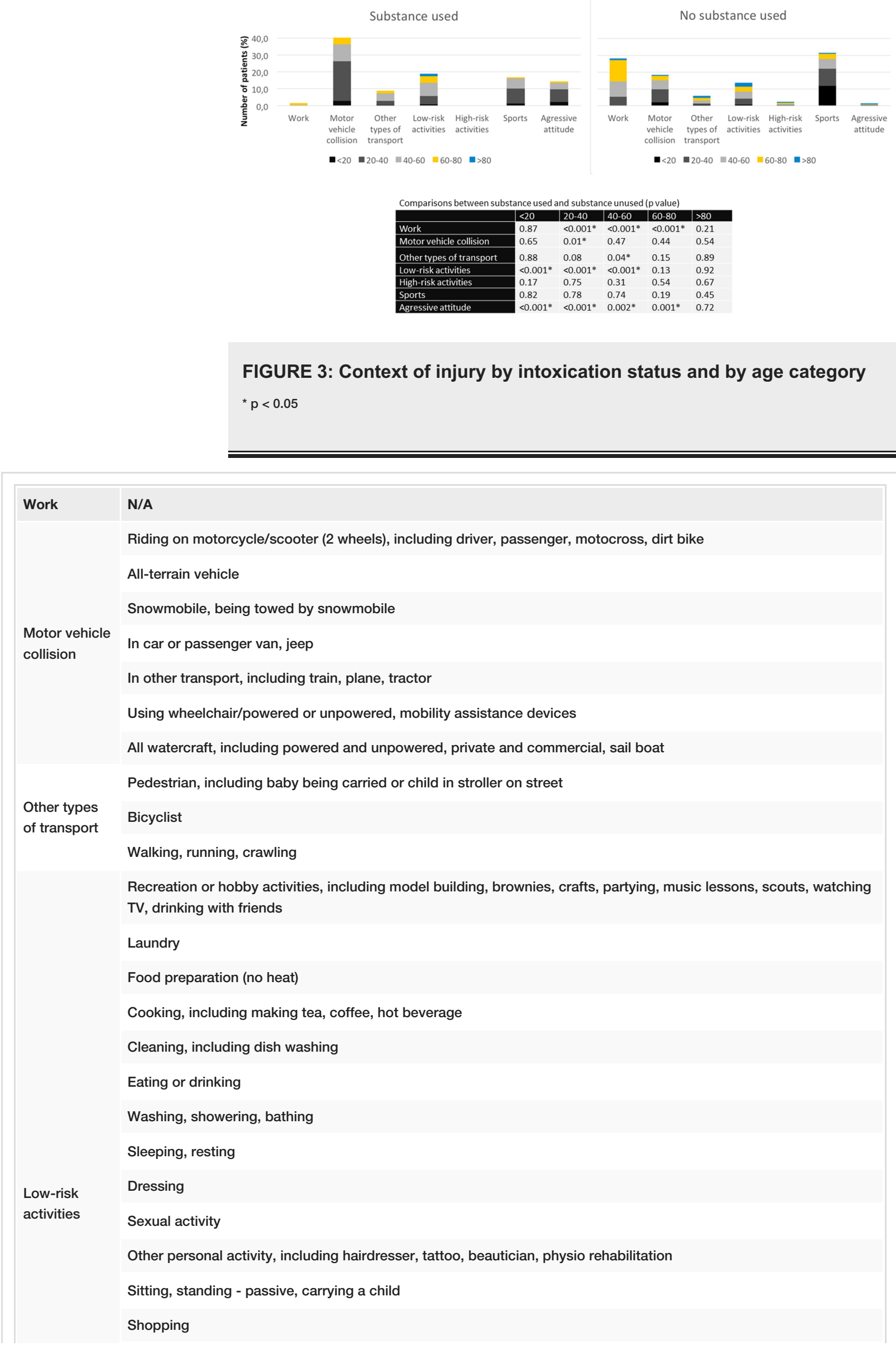




\section{Cureus}

\begin{tabular}{|c|c|}
\hline & Being cared for, including patient in hospital, MD's office; person being dressed, bathed, fed \\
\hline & Playing, including climbing inside at home \\
\hline & $\begin{array}{l}\text { Other activity inside/outside, including bringing in groceries, taking out garbage, loading/unloading vehicle, } \\
\text { household chores, lifting vacuum cleaner, getting down from a chair, cutting metal }\end{array}$ \\
\hline & Formal educational activities, including homework, teaching/coaching sports \\
\hline & Volunteer (unpaid work outside home), including fundraising \\
\hline \multirow{5}{*}{$\begin{array}{l}\text { High-risk } \\
\text { activities }\end{array}$} & Electrical work \\
\hline & Do-it-yourself, including plumbing, carpentry, etc. \\
\hline & Vehicle maintenance \\
\hline & Moving furniture \\
\hline & Gardening, yard work, including chopping wood, cutting trees, shoveling snow, taking in wood \\
\hline \multirow{3}{*}{ Sports } & Sports, organized competition or practice and physical recreation activities, including lessons, physical education \\
\hline & $\begin{array}{l}\text { Sports, informal and physical recreation activities including tobogganing, trampolining, dancing (in home), hide-and- } \\
\text { seek, tag, playfighting }\end{array}$ \\
\hline & Sports, not specified \\
\hline \multirow{3}{*}{$\begin{array}{l}\text { Aggressive } \\
\text { attitude }\end{array}$} & Had tantrum, loss of temper, loss of control (only one person involved) \\
\hline & Quarrel, aggression, fight, riot (two or more people involved) \\
\hline & $\begin{array}{l}\text { Intent to cause effect or reaction (intent to cause effect to oneself or reaction by another), including acting out, self- } \\
\text { harm }\end{array}$ \\
\hline $\begin{array}{l}\text { Information } \\
\text { missing }\end{array}$ & N/A \\
\hline
\end{tabular}

\section{TABLE 3: Grouping of contexts of injury}

\section{Additional Information \\ Disclosures}

Human subjects: Consent was obtained by all participants in this study. Comité d'éthique du CHU de Québec issued approval NA. The Ethics Committee has concluded that no ethics application is required for the analyses of data from CHIRPP database. Animal subjects: All authors have confirmed that this study did not involve animal subjects or tissue. Conflicts of interest: In compliance with the ICMJE uniform disclosure form, all authors declare the following: Payment/services info: All authors have declared that no financial support was received from any organization for the submitted work. Financial relationships: All authors have declared that they have no financial relationships at present or within the previous three years with any organizations that might have an interest in the submitted work. Other relationships: All authors have declared that there are no other relationships or activities that could appear to have influenced the submitted work.

\section{References}

1. London JA, Battistella FD: Testing for substance use in trauma patients: are we doing enough? . Arch Surg. 2007, 142:633-638. 10.1001/archsurg.142.7.633

2. Drug use. (2019). Accessed: September 05, 2020: https://ourworldindata.org/substance-use.

3. Sornpaisarn B, Sornpaisarn S, Shield KD, Rehm J: Alcohol use and injury risk in Thailand: a case-crossover emergency department study. Drug Alcohol Rev. 2020, 39:539-545. 10.1111/dar.13094

4. Agrawal V, Amos JD: The association between illicit drug use and infectious complications among trauma patients. Eur J Clin Microbiol Infect Dis. 2017, 36:447-450. 10.1007/s10096-016-2815-5

5. Harford TC, Yi H-y, Chen CM, Grant BF: Substance use disorders and self- and other-directed violence among adults: results from the National Survey on drug use and health. J Affective Dis. 2018, 225:365-373. 10.1016/j.jad.2017.08.021

6. Loiselle JM, Baker MD, Templeton JM, Schwartz G, Drott H: Substance abuse in adolescent trauma . Ann Emerg Med. 1993, 22:1530-1534. 10.1016/S0196-0644(05)81253-3

7. McCabe S: Substance use and abuse in trauma: implications for care . Crit Care Nurs Clin North Am. 2006, 18:371-385. 10.1016/j.ccell.2006.05.002 
8. Cherpitel CJ: Alcohol and injuries: a review of international emergency room studies . Addiction. 1993, 88:923-937. 10.1111/j.1360-0443.1993.tb02110.x

9. Cherpitel CJ: Focus on: the burden of alcohol use--trauma and emergency outcomes . Alcohol Res. 2013, 35:150-154.

10. Falvo F, Schmid A: Bridging the gap: drug and alcohol screening in adolescent trauma patients . J Emerg Nurs. 2018, 44:325-330. 10.1016/j.jen.2018.01.002

11. Cherpitel CJ, Martin G, Macdonald S, Brubacher JR, Stenstrom R: Alcohol and drug use as predictors of intentional injuries in two emergency departments in British Columbia. Am J Addict. 2013, 22:87-92. 10.1111/j.1521-0391.2013.00316.x

12. Canadian hospitals injury reporting and prevention program. (2016). Accessed: September 05, 2020: https://www.canada.ca/en/public-health/services/injury-prevention/canadian-hospitals-injury-reportingprevention-prog....

13. Zou G: A modified Poisson regression approach to prospective studies with binary data . Am J Epidemiol. 2004, 159:702-706. 10.1093/aje/kwh090

14. Salhi BA, White MH, Pitts SR, Wright DW: Homelessness and emergency medicine: a review of the literature. Acad Emerg Med. 2018, 25:577-593. 10.1111/acem.13358

15. Hinsliff-Smith K, McGarry J: Understanding management and support for domestic violence and abuse within emergency departments: a systematic literature review from 2000-2015. J Clin Nurs. 2017, 26:40134027. 10.1111/jocn.13849

16. Mercier E, Nadeau A, Brousseau A, et al.: Elder abuse in the out-of-hospital and emergency department settings: a scoping review. Ann Emerg Med. 2020, 75:181-191. 10.1016/j.annemergmed.2019.12.011

17. Miller IW, Camargo CA Jr, Arias SA, et al.: Suicide prevention in an emergency department population: the ED-SAFE study. JAMA Psychiatry. 2017, 74:563-570. 10.1001/jamapsychiatry.2017.0678

18. Barata IA, Shandro JR, Montgomery M, et al.: Effectiveness of SBIRT for alcohol use disorders in the emergency department: a systematic review. Western J Emerg Med. 2017, 18:1143-1152. 10.5811/westjem.2017.7.34373

19. Nunn J, Erdogan M, Green RS: The prevalence of alcohol-related trauma recidivism: a systematic review . Injury. 2016, 47:551-558. 10.1016/j.injury.2016.01.008

20. Kapur N: Management of self-harm in adults: which way now? . Br J Psychiatry. 2005, 187:497-499. 10.1192/bjp.187.6.497

21. Kapur N, Cooper J, Rodway C, Kelly J, Guthrie E, Mackway-Jones K: Predicting the risk of repetition after self harm: cohort study. BMJ. 2005, 330:394-395. 10.1136/bmj.38337.584225.82

22. Rao DP, Abramovici H, Crain J, Do MT, McFaull S, Thompson W: The lows of getting high: sentinel surveillance of injuries associated with cannabis and other substance use. Can J Public Health. 2018, 109:155-163. 10.17269/s41997-018-0027-8

23. van der Westhuizen C, Wyatt G, Williams JK, Stein DJ, Sorsdahl K: Prevalence and predictors of mental disorders in intentionally and unintentionally injured emergency center patients. J Nerv Men Dis. 2014, 202:638-646. 10.1097/NMD.0000000000000176

24. Jetelina KK, Reingle Gonzalez JM, Brown CV, Foreman ML, Field C: Acute alcohol use, history of homelessness, and intent of injury among a sample of adult emergency department patients. Violence Vict. 2017, 32:658-670. 10.1891/0886-6708.VV-D-16-00069

25. Moden B, Ohlsson H, Merlo J, Rosvall M: Risk factors for diagnosed intentional self-injury: a total population-based study. Eur J Public Health. 2013, 24:286-291. 10.1093/eurpub/ckt066 